\title{
Studies on the Interaction between Macrophages and Leptospires
}

\author{
By MARINO CINCO, ${ }^{1 *}$ ELENA BANFI ${ }^{1}$ AND MARIA ROSA SORANZO ${ }^{2}$ \\ ${ }^{1}$ Institute of Microbiology and ${ }^{2}$ Institute of General Pathology, University of Trieste, \\ Trieste, Italy
}

(Received 22 September 1980)

\begin{abstract}
Guinea-pig macrophages exerted no bactericidal activity against either a virulent or a saprophytic strain of leptospira during a $120 \mathrm{~min}$ period of contact at $37^{\circ} \mathrm{C}$. However, the same macrophages exhibited weak phagocytic powers towards these two strains of leptospira over a similar period of time.
\end{abstract}

\section{INTRODUCTION}

The first stage in a leptospiral infection is characterized by invasiveness. In the first few days following infection leptospires can be isolated from the blood, thus suggesting that they are able to evade for a time the natural defences of the body, namely the opsonizing and killing activity of the antibody-complement system and phagocytosis. Normal serum exerts its antileptospiral activity primarily against saprophytic not pathogenic leptospires (Johnson \& Muschel, 1965, 1966). Of the pathogenic species only avirulent strains are sensitive to serum containing specific antibodies and complement (Johnson \& Harris, 1967a). This led Johnson \& Harris (1967 a) to suggest that the basis for the virulence of pathogenic species lay in their ability to withstand the leptospiricidal activity of the host antibody-complement system and thus to multiply in vivo. The role of phagocytosis in the control of leptospiral infection was investigated by Faine (1964) and Faine et al. (1964) who, on the basis of microscopic observations, reported that both mouse and guinea-pig macrophages engulfed leptospires. However, neither the cytotoxic effect of the leptospires on the macrophages nor their intracellular survival within the macrophages was investigated. The present study was undertaken to examine the interaction between a macrophage population and a suspension of either pathogenic or saprophytic leptospires, in order to ascertain whether their invasiveness was indeed associated with their ability to survive within the phagocytic cell. In particular, the ability of macrophages to kill leptospires was investigated. To this end an accurate and reproducible method for obtaining viable counts of leptospires was developed. By the same cultural technique and in conjunction with electron microscopic observations, the rate of phagocytosis was also evaluated.

\section{METHODS}

Organisms and media. Two strains of leptospira were used: the virulent strain PB-3 belonging to serogroup Icterohaemorrhagiae, serovar copenhageni and having an $\mathrm{LD}_{50}$ for the guinea-pig of between $10^{6}$ and $10^{7}$ organisms $\mathrm{ml}^{-1}$; and the saprophytic strain Isola Sacra 1, serogroup Doberdo, serovar isolasacra, from our reference collection. The organisms were grown in the liquid medium devised by Ellinghausen \& McCullough (1965) for 3 to $5 \mathrm{~d}$ at $37^{\circ} \mathrm{C}$, harvested by centrifugation, washed twice and finally resuspended in Krebs-Ringer phosphate solution (KRP), pH 7.4 to a density of $1 \times 10^{7}$ to $3 \times 10^{7}$ organisms $\mathrm{ml}^{-1}$ (counted in a Thoma counting chamber, unless otherwise stated). Viable counts of leptospires were made on PLM5 medium (Reheis Chemical Co., Armour Pharmaceutical Co., Phoenix, Ariz., U.S.A.) solidified with $1 \%$ (w/v) Bacto agar (Difco); PLM5 is a complete albumin Tween 80 medium devised by Johnson \& Harris $(1967 b)$.

Macrophages. Guinea-pig macrophages were obtained from peritoneal exudates collected $4 \mathrm{~d}$ after intra- 
peritoneal injection of $1 \%(\mathrm{w} / \mathrm{v})$ sterile casein in $0.85 \%(\mathrm{w} / \mathrm{v}) \mathrm{NaCl}$ in distilled water. The cells were harvested by centrifugation at $250 \mathrm{~g}$ for $7 \mathrm{~min}$, washed once and resuspended in $\mathrm{KRP}$ containing $0.5 \mathrm{mM}-\mathrm{CaCl}_{2}$ and $5 \%(\mathrm{v} / \mathrm{v}$ ) heat-inactivated rabbit serum. The cells were counted in a Thoma counting chamber and adjusted to a density of 2 $\times 10^{6}$ to $4 \times 10^{6}$ cells $\mathrm{ml}^{-1}$. Examination of Giemsa-stained preparations revealed that more than $95 \%$ of the cells possessed typical macrophage morphology. The phagocytic capacity of a suspension of macrophages was determined by adding to a sample of the suspension an equal volume of a suspension of an autoclaved strain of Staphylococcus aureus $\left(10^{7}\right.$ organisms $\mathrm{ml}^{-1}$ ) in the presence and absence of $0.01 \mathrm{M}-N$-ethylmaleimide, a known inhibitor of phagocytosis. After incubation for $5 \mathrm{~min}$ at $37^{\circ} \mathrm{C}$ the mixture was centrifuged and washed once with KRP. From the final deposit, films were made, stained by the May-Grünwald-Giemsa method and examined microscopically. The percentage of cells that had ingested the $S$. aureus was considered as the 'phagocytic capacity' of that macrophage population. The potential bactericidal activity of a suspension of macrophages was evaluated as described below using a sensitive strain of Escherichia coli $\mathrm{K} 12 \lambda^{-}$, and nutrient agar plates for viable counting. When tested in this manner the different populations of macrophages examined for their activity towards leptospires were found to have a 'phagocytic capacity' against the autoclaved strain of $S$. aureus ranging from 82 to $90 \%$ dropping to $9 \%$ in the presence of $N$-ethylmaleimide, and a bactericidal effect on $E$. coli K12 $\lambda^{-}$, resulting in a 100-fold decrease in the number of viable organisms after $30 \mathrm{~min}$ incubation in the presence of macrophages.

Assessment of bactericidal and phagocytic activity of macrophages against leptospires. The method of McRipley \& Sbarra (1967) for the assessment of macrophage activity against bacteria was followed, with a few modifications. For each experiment, tubes were prepared containing equal volumes of a suspension of $1 \times 10^{7}$ to 3 $\times 10^{7}$ leptospires $\mathrm{ml}^{-1}$ and of a suspension of $2 \times 10^{6}$ to $4 \times 10^{6}$ macrophages $\mathrm{ml}^{-1}$. The optimum bacteria to phagocytes ratio was found to be between $3: 1$ and $8: 1$. Control tubes contained equal volumes of the suspension of leptospires and of KRP. Samples of these mixtures for the assessment of macrophage activity were taken immediately and after 30,60 and $120 \mathrm{~min}$ incubation at $37^{\circ} \mathrm{C}$ in a shaking water bath.

The bactericidal activity was assessed by taking $0.1 \mathrm{ml}$ of the mixture and adding $0.9 \mathrm{ml} 0.5 \%(\mathrm{w} / \mathrm{v})$ sterile saponin to lyse the phagocytes and release the intracellular leptospires. This concentration of saponin was found to be non-toxic for leptospires. The saponin-containing mixtures were allowed to stand for $15 \mathrm{~min}$ at room temperature, and then serial 10-fold dilutions were made in phosphate-buffered saline, $\mathrm{pH} \mathrm{7.4}$. Three $0.1 \mathrm{ml}$ samples of each dilution were spread on PLM5 agar plates and incubated aerobically at $30^{\circ} \mathrm{C}$. Colonies of the saprophytic strain developed after $6 \mathrm{~d}$ and those of the pathogenic strain after $10 \mathrm{~d}$. No increase in the number of colonies was observed after more prolonged incubation. From the mean number of colony-forming units (c.f.u.) present in each series of dilutions the mean number of viable leptospires $\mathrm{ml}^{-1}$ was calculated. Preliminary repeated assays showed that the method gave good reproducible results.

The phagocytic activity was assessed by taking a $0.1 \mathrm{ml}$ sample of each mixture which was then twice washed in $10 \mathrm{ml}$ cold KRP and centrifuged at $250 \mathrm{~g}$ for $7 \mathrm{~min}$ at $4{ }^{\circ} \mathrm{C}$ to free the leptospires trapped between macrophages. The supernatants from the two washings were pooled and from the pool serial 10-fold dilutions made. The pellet was suspended in $0.1 \mathrm{ml} \mathrm{KRP}$ plus $0.9 \mathrm{ml} 0.5 \%(\mathrm{w} / \mathrm{v})$ sterile saponin to lyse the phagocytes and release the intracellular leptospires. After standing for $15 \mathrm{~min}$ at room temperature serial 10 -fold dilutions of the mixture were again made. Both series of dilutions were assayed as described above to determine the number of c.f.u. $\mathrm{ml}^{-1}$ in each fraction, i.e. the number of free-living leptospires and those associated with, either intracellularly or adherent to, the phagocytes.

Electron microscopy. Samples of a suspension of macrophages in plastic tubes were challenged with either leptospira strain PB-3 or strain Isola Sacra 1, at a phagocytes to leptospires ratio of 1:50, and incubated at $37^{\circ} \mathrm{C}$. After $5,30,60$ or $120 \mathrm{~min}$, the incubation was stopped by adding glutaraldehyde in cacodylate buffer, $\mathrm{pH} 7 \cdot 4$, to give final concentrations of $2 \%(\mathrm{w} / \mathrm{v})$ and $0.1 \mathrm{M}$, respectively. Further fixation at $4{ }^{\circ} \mathrm{C}$ for 30 min was done with $1 \%(\mathrm{w} / \mathrm{v}) \mathrm{OsO}_{4}$ in the same buffer. Samples were dehydrated in graded ethanol series and embedded in Dow epoxy resin 332 (Lockwood, 1964). Ultrathin sections were cut with an LKB Ultratome III, stained with uranyl acetate and lead citrate (Venable \& Coggeshall, 1965) and examined in a Philips 300 electron microscope.

Statistical analysis. To evaluate the significance of the experiments the analysis of variance implying a regression was used (Lison, 1961). From the $F$ values obtained the levels of significance were deduced.

\section{RESULTS}

Bactericidal activity against leptospires. No bactericidal activity against either the virulent leptospira strain PB-3 or the saprophytic strain Isola Sacra 1 was exhibited by the macrophages; the viable counts of leptospires in the presence and absence of macrophages were not significantly different throughout the 120 min period of incubation.

Phagocytic activity against leptospires. During $120 \mathrm{~min}$ incubation of mixtures of leptospires and macrophages there was a significant increase in the number of c.f.u. $(\mathrm{ml}$ 


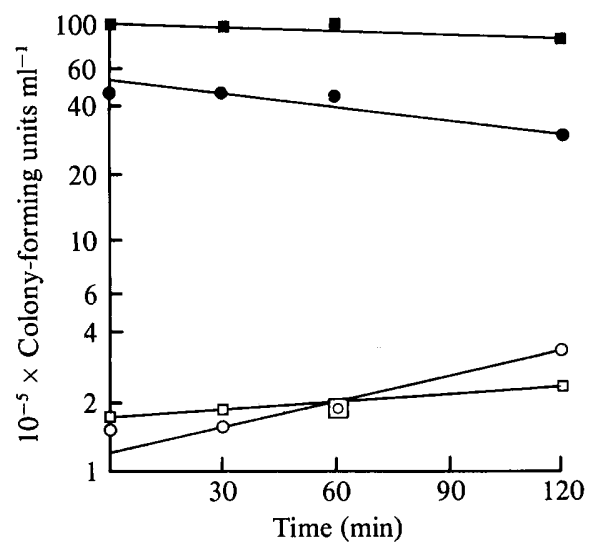

Fig. 1. Phagocytosis of leptospires incubated with a suspension of guinea-pig macrophages. After different periods of incubation, mixtures of leptospires and macrophages were centrifuged and the numbers of leptospires were determined in the pellet of macrophages and in the supernatant: virulent strain PB-3, pellet (O) and supernatant (O); saprophytic strain Isola Sacra 1, pellet $(\square)$ and supernatant $(\square)$. Level of significance for plot $O=0.001, O=0.001, \square=0.001$ and $\square=0.05$.

mixture $)^{-1}$ associated with the macrophages. For both the virulent strain PB-3 and the saprophytic strain Isola Sacra 1 this increase was significant at the 0.001 level. There was a concomitant decrease in the number of c.f.u. ( $\mathrm{ml}$ mixture $)^{-1}$ in the supernatants. The level of significance of the decrease was less the greater the density of the organisms in the mixture at the beginning of the period of incubation (Fig. 1). These findings, based on the results of repeated experiments, suggest that a certain number of both virulent and saprophytic leptospires slowly become associated with the macrophages over a period of $120 \mathrm{~min}$.

Electron microscopy. After 5 or 30 min contact between macrophages and leptospires, electron microscopy revealed that, in general, the organisms were outside the macrophage membranes and that, in particular, the macrophages appeared to be in a resting state (Fig. $2 a$ ). Only 6 to $10 \%$ of the phagocytic cells had leptospires within the cytoplasm. This finding may represent the ingestion of a small population of dead leptospires, and is not considered to be significant. After incubation for $60 \mathrm{~min}$ or longer, more macrophages contained leptospires, and by the end of 120 min incubation $30 \%$ of the phagocytic cells contained leptospires. Some of the ingested leptospires were within vacuoles whilst others appeared free within the cytoplasm having apparently penetrated the plasma membrane (Fig. 2b,c). The structure of the bacteria appeared unchanged.

\section{DIS CUSSION}

The data presented in this paper indicate that neither the virulent nor the saprophytic strain of leptospira is sensitive to the bactericidal action of phagocytes during the $2 \mathrm{~h}$ of the test. In addition, as shown by electron microscopy, no significant phagocytosis takes place during the first $30 \mathrm{~min}$ incubation. However, both microscopic and cultural studies indicated that after longer periods of incubation some leptospires are associated with phagocytes and their number increases with time. These findings are in contrast to those obtained with other bacteria such as $S$. aureus, E. coli, Listeria and Brucella. Furthermore, among the Spirochaetales, Treponema pallidum is not phagocytosed unless immune serum is present. Even then phagocytosis occurs at a very low rate and becomes evident only after $4 \mathrm{~h}$ incubation (Schell et al., 1975; Lukehart \& Miller, 1978). The presence of leptospires within phagocytes may represent the result of either phagocytosis or the active penetration of these micro-organisms into macrophages. It is not possible to decide between these two alternatives, 

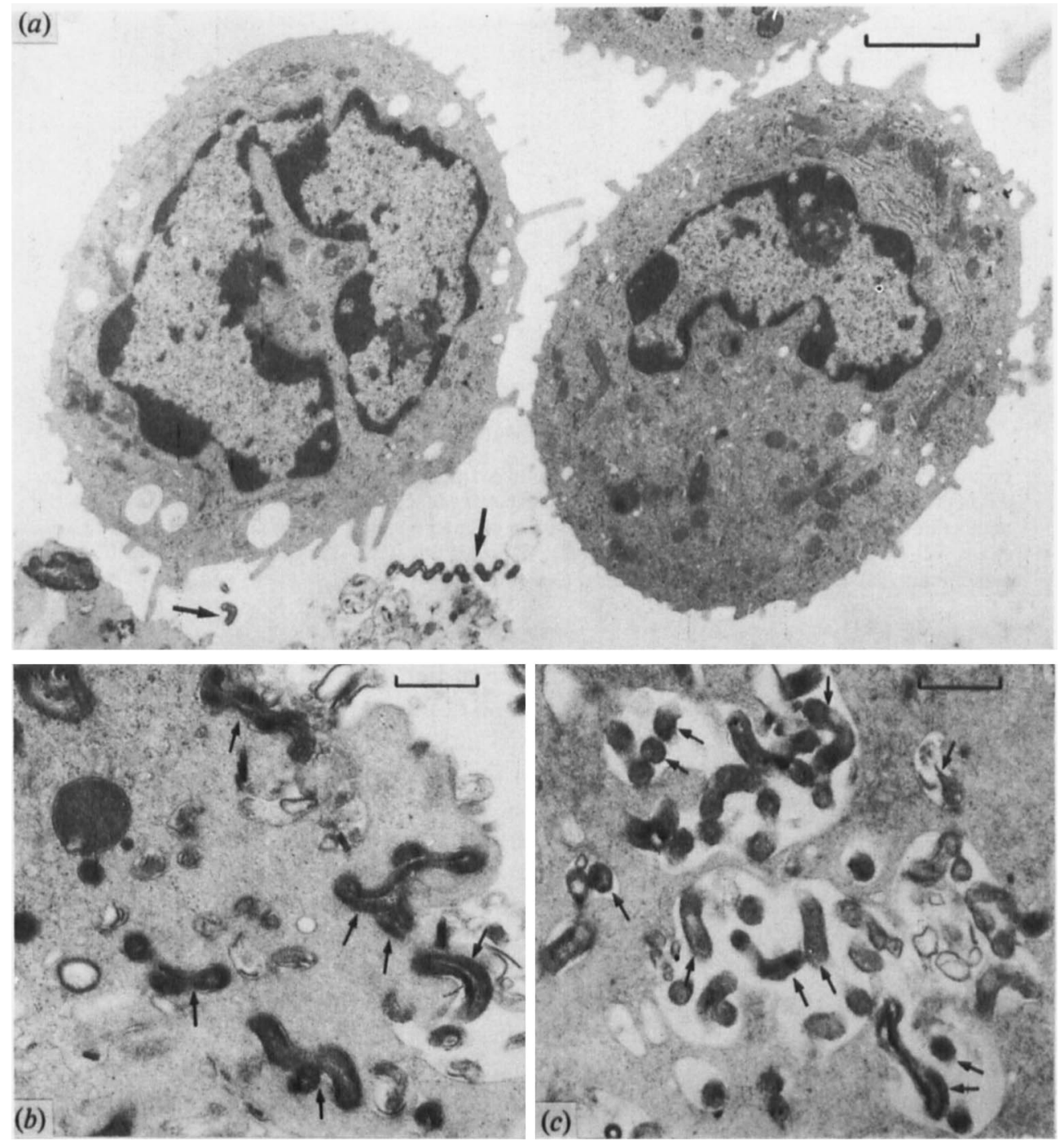

Fig. 2. Electron micrographs showing the phagocytosis of Isola Sacra 1 leptospires by guinea-pig macrophages: (a) after 30 min incubation, organisms (arrowed) are outside the macrophages; $(b)$ after $60 \mathrm{~min}$ incubation, with organisms penetrating the cytoplasm; (c) after 60 min incubation, with organisms visible inside vacuoles. The bar markers represent $2 \mu \mathrm{m}$ in $(a)$ and $0.5 \mu \mathrm{m}$ in $(b)$ and $(c)$.

though data in the literature (Rose et al., 1966; Faine et al., 1975) would support the latter hypothesis. The most significant conclusion that can be drawn from these studies is that leptospires, both outside and inside the phagocytic cells, are apparently still fully capable of multiplication. This suggests that macrophages cannot be considered an efficient defence against infective leptospires at least at the onset of the infection in a non-immune host.

The authors are indebted to Dr P. L. Patriarca for his helpful suggestions. The research was in part supported by a grant from the University of Trieste (Fondo Incentivante) to Dr M. Cinco and in part by grant no. 79.00984.04 from the National Research Council of Italy, and by a grant from the University of Trieste (Fondo Incentivante) to Dr P. L. Patriarca. 


\section{REFERENCES}

Ellinghausen, H. C. \& McCullough, W. G. (1965). Nutrition of Leptospira pomona and growth of 13 other serotypes: fractionation of oleic albumin complex and a medium of bovine albumin and polysorbate 80. American Journal of Veterinary Research 26, 45-51.

FAINE, S. (1964). Reticuloendothelial phagocytosis of virulent leptospires. American Journal of Veterinary Research 25, 830-835.

Faine, S., Shahar, A. \& Aronson, M. (1964). Phagocytosis and its significance in leptospiral infection. Australian Journal of Experimental Biology and Medical Science 42, 579-588.

Faine, S., Hudson, R. E. \& Frank, R. (1975). Pathogenic mechanism in leptospirosis cytopathic effects. Proceedings of the National Symposium on Leptospirosis, Leptospira and other Spirochaeta, Bucharest, pp. 145-149.

Johnson, R. C. \& HARRIS, V. G. (1967a). Antileptospiral activity of serum. II. Leptospiral virulent factors. Journal of Bacteriology 93, 513-519.

Johnson, R. C. \& HARRIS, V. G. (1967b). Differentiation of pathogenic and saprophytic leptospires. I. Growth at low temperatures. Journal of Bacterio$\log y$ 94, 27-31.

Johnson, R. C. \& Muschel, L. H. (1965). Antileptospiral activity of normal serum. Journal of Bacterio$\log y$ 89, 1625-1626.

Johnson, R. C. \& Muschel, L. H. (1966). Antilepto- spiral activity of serum. I. Normal and immune serum. Journal of Bacteriology 91, 1403-1409.

Lison, L. (1961). Statistica Applicata alla Biologia Sperimentale. Milano: Casa Editrice Ambrosiana.

Lockwood, W. R. (1964). A reliable and easily sectioned epoxy embedding medium. Anatomical Record 150, 129-140.

Lukehart, S. A. \& Miller, J. N. (1978). Demonstration of the in vitro phagocytosis of Treponema pallidum by rabbit peritoneal macrophages. Journal of Immunology 121, 2014-2024.

MCRIPLEY, R. J. \& SBARRA, A. J. (1967). Role of the phagocyte in host-parasite interactions. XI. Relationship between stimulated oxidative metabolism and hydrogen peroxide formation and intracellular killing. Journal of Bacteriology 94, 14171424.

Rose, G. W., Eveland, W. C. \& Ellinghausen, H. C. (1966). Mechanism of tissue cell penetration by Leptospira pomona: active penetration studies in vitro. American Journal of Veterinary Research 27, 1461-1471.

SCHELl, R., Musher, D., Jacobson, K., Schnethelm, P. \& Simmons, C. (1975). Effect of macrophage activation on infection with Treponema pallidum. Infection and Immunity 12, 505-511.

Venable, J. H. \& Coggeshall, R. (1965). A simplified lead citrate stain for use in electron microscopy. Journal of Cell Biology 25, 407-408. 